Rev. Latinoam. Psicopat. Fund., São Paulo, 20(3), 609-612, set. 2017

http://dx.doi.org/10.1590/1415-4714.2017v20n3p609.14

Letras do sintoma

Sonia Leite \& Terezinha Costa (Orgs.)

Rio de Janeiro: Contra Capa/Corpo Freudiano Seção RJ, 2016, 168 págs.

\title{
Resistir e insistir: o trabalho da psicanálise
}

Rosa Maria Carvalhal Silva Maranhão*1

A coletânea Letras do sintoma constitui-se como contraponto importante no panorama social atual, mostrando a potência, o frescor e a pertinência da psicanálise nos dias de hoje, do ponto de vista da sua especificidade teórico/conceitual e da prática clínica! Cada texto apresenta nas revisões e articulações teóricas, nos exemplos clínicos, nas questões propostas, esse movimento de resistência e de insistência, característico do campo psicanalítico... Revela ainda, no seu modo de escrita, no formato de seus textos, a sua concepção de Escola, que não supõe nem pretende um conhecimento fechado, resistindo à padronização e ao discurso de mestria, estimulando e acolhendo a diversidade

*1 Doutora pela Pontifícia Universidade Católica do Rio de Janeiro - PUC-RJ (Rio de Janeiro, $\mathrm{RJ}, \mathrm{Br})$. 
de trajetórias, no campo dos estudos e das práticas clínicas, trazendo à luz o estilo e a marca de cada um dos autores. Nesse movimento, explicita ainda a sua concepção de formação como trabalho permanente, que se dá através e nos percursos singulares, marcados pela incompletude. Assim, os textos, ainda que falem de temáticas semelhantes, o fazem por meio de cortes, encadeamentos próprios, não rematados, ou seja, em movimento, que instigam, levando o leitor a produzir e a caminhar.

A primeira parte do livro, não por acaso, é composta de textos que tematizam a histeria, "o princípio de tudo". Assim, os textos alocados em "Na histeria", apresentam recortes teóricos que trazem sua história, reavivando nossa memória, e exemplos clínicos que assinalam sua pujança no cenário atual. Mostrar a histeria, com seus travestimentos, suas novas roupagens, faz diferença neste momento de mudanças nos manuais psicopatológicos, onde ela é, magicamente, retirada da cena principal! Hoje, como ontem, a histeria continua confundindo os olhares, demandando escuta, deciframento de suas letras, no um a um, do caso a caso. E isso implica trabalho e tempo! Alguns textos assinalam, ainda, a importância de uma diferenciação mais rigorosa acerca dos modos de sofrimento que "escolhem" o corpo como cenário ou, dito de outra maneira, se inscrevem no corpo. De forma clara, ou nas entrelinhas, os autores ressaltam o papel do psicanalista, da sua escuta e do seu desejo na iniciação e sustentação do processo de análise.

"Nas obsessões e nas fobias", que constitui a segunda parte da coletânea, a angústia é trazida por meio de aportes teóricos e de casos clínicos. Há consenso com relação à sua centralidade na teoria e na clínica psicanalíticas, bem como quanto ao seu papel de sinalizador de que há algo a ser evitado, gerando afetos diversos. Assim, a escrita dos textos vai re-velando o sofrimento, nas repetições incessantes dos obsessivos, na ambivalência que entorpece sua vontade, impedindo-os de tomar decisões ou, ainda, no que diz respeito à fobia, nas tentativas de criar estratégias de evitação do objeto fóbico, que transforma, reduz e delimita a geografia do mundo como forma de conter e se defender da angústia. Nessa parte da coletânea, alguns textos tratam, ainda, do tema pela via do estranho, do Unheimlich, por meio de fábulas, contos, articulando conceitos teóricos a comportamentos, mitos, fantasias presentes na cultura, trazendo à cena o traumático, a fantasia de castração e os medos infantis em seu papel na arquitetura da fobia.

Por último, a terceira parte, "Nas artes e na cultura", nos traz inusitadas reflexões sobre as artes, em especial a arte contemporânea, a literatura e o cinema em suas articulações com o tema clínico da coletânea. Assim, por 


\section{RESENHAS BIBLIOGRÁFICAS}

exemplo, no que diz respeito à literatura, através da estruturação do texto, seus cortes, ritmos e leituras não lineares, há um favorecimento de construções outras, fora do texto, com outras significações. Também no cinema, a utilização de determinados recursos na sucessão de imagens, a sua pouca definição, os sons, o uso de claro-escuro, podem provocar a sensação do estranho no espectador, conduzindo-o para algo que está além da evidência mesma da obra. No que diz respeito à arte contemporânea, com suas instalações surpreendentes, o que se destaca é o convite para o sujeito experimentar novas posições no mundo. Essa modalidade de arte produz deslizamentos, fendas, desconforto, que colocam o sujeito, literalmente, fora de sua casa! Os autores desses artigos apontam, de modo geral, que as artes são produtoras de importantes reflexões sobre questões discutidas pela psicanálise, podendo fazer avançar a própria teoria, alargando, também, a escuta do psicanalista. Os textos, ainda, levantam discussões sobre a contemporaneidade, seus excessos e o papel da psicanálise nesse cenário.

Para finalizar queremos ressaltar a importância dessa coletânea que reafirma a Psicanálise, e a consistência do seu arcabouço teórico-técnico e metodológico na cena contemporânea. Cena marcada por um excesso de ofertas terapêuticas, pela extinção e/ou renomeação de nosografias e nosologias, pelo silenciamento do sintoma, pelas práticas, enfim, que tentam excluir o sujeito, uniformizadas, rápidas e obedientes a uma lógica organicista. É por isso que, ainda hoje, como sempre, a psicanálise se traduz pelo resistir e pelo insistir com o trabalho do inconsciente...

Citação/Citation: Maranhão, R. M. C. S. (2017, setembro). Resistir e insistir: o trabalho da psicanálise. Resenha do livro Letras do sintoma. Revista Latinoamericana de Psicopatologia Fundamental, 20(3), 609-612. http://dx.doi.org/10.1590/1415-4714.2017v20n3p609.14 Editores do artigo/Editors: Profa. Dra. Sonia Leite

Recebido/Received: 15.1.2017 / 1.15.2017 Aceito/Accepted: 18.3.2017 / 3.18.2017 


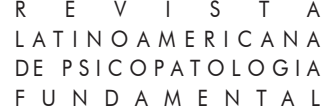

Copyright: (C) 2009 Associação Universitária de Pesquisa em Psicopatologia Fundamental/ University Association for Research in Fundamental Psychopathology. Este é um artigo de livre acesso, que permite uso irrestrito, distribuição e reprodução em qualquer meio, desde que o autor e a fonte sejam citados / This is an open-access article, which permits unrestricted use, distribution, and reproduction in any medium, provided the original authors and sources are credited.

\section{Rosa Maria Carvalhal Silva Maranhão}

Psicóloga; Psicanalista; Doutora em Psicologia Clínica pela Pontifícia Universidade Católica do Rio de Janeiro - PUC-RJ. (Rio de Janeiro, RJ. Br).

Rua das Laranjeiras, 322/402

612 22240-000 Rio de Janeiro, RJ, Br

romaranhao@gmail.com

This is an open-access article, which permits unrestricted use, distribution, and reproduction in any medium for non-commercial purposes provided the original authors and sources are credited. 